\title{
LA NOCIÓN ELLULIANA DE LA TÉCNICA
}

\section{Arturo Damián Sanchís *}

\section{LA TÉCNICA}

La confusión entre «técnica» y «máquina» es muy frecuente. Habitualmente, se entiende que la historia de la técnica se reduce a la historia de las máquinas. Sin perjuicio de que el origen de la técnica haya que buscarlo en la mecánica, lo cierto es que ha devenido del todo autónoma respecto de aquélla. La técnica excede las aplicaciones mecánicas, propias de la actividad industrial. Todavía más: «la máquina es la que hoy depende, en todo, de la técnica y apenas si la representa en una pequeña parte. $\rangle^{1}$ La mecánica no es más que una faceta de la técnica, y ni siquiera la más importante. La máquina es un síntoma y un indicador de la técnica. Y ésta, la expresión consciente del poder de la mecánica, el más visible elemento del fenómeno técnico.

Ahora bien, desde el punto de vista metodológico, no habría dificultades que impidieran aceptar un estudio de la técnica a partir de la mecánica, entendida como un tipo ideal weberiano de las aplicaciones técnicas. Al fin y al cabo, la técnica conlleva una tendencia fatal: la mecanización de todo lo que toca. ${ }^{2} \mathrm{Y}$ las relaciones humanas no escapan a ese designio. ${ }^{3} \mathrm{Ni}$ siquiera la concepción adorniana de la técnica llegaría a vislumbrar el designio holista del fenómeno técnico: «Los hombres tienden a tomar la técnica por la cosa misma, a considerarla un fin autónomo, una fuerza con ser propio, y por eso, a olvidar que es la prolongación

\footnotetext{
* Profesor del CEU San Pablo de Valencia. El presente artículo forma parte de la Tesis Doctoral del autor La Técnica: fenómeno, sistema y discurso. La crítica de la racionalidad técnica en la obra de Jacques Ellul, dirigida por el profesor Dr. Octavio Uña Juárez.
} 
del brazo humano. Los medios -y la técnica es un conjunto de medios para la autoconservación- son fetichizados porque los fines -una vida humana digna- han sido vetados y expulsados de la conciencia de los hombres.» ${ }^{4}$

El orden mecánico necesitaba una fundamentación y una legitimación. La primera la encontró en la creciente racionalización de «los dominios abstractos.» La segunda, en la eficacia para todos los órdenes de la acción. «La organización sitúa a la máquina donde debe hacerlo y espera de ella lo que deba esperar.» ${ }^{5} \mathrm{Y}$ cuando la técnica se hace autónoma, desmiente una relación principal entre el hombre y la mecánica: en el orden mecánico, la máquina era un objeto, pero en el orden técnico, el objeto es el hombre. La técnica arrumba la subjetividad individual por la vía de la objetivación de las subjetividades, haciendo del sujeto una abstracción indefectiblemente tomada como un objeto. ${ }^{6}$ Otra diferencia esencial entre la mecánica y la técnica. Si la máquina era una forma superior de «saber-hacer», la mecanización es la extensión de esa modalidad de conocimiento a muchos ámbitos extraños al mundo propio de la máquina. Y la técnica, el último estadio de la mecánica. Un nuevo principio de dominio que envuelve al pensamiento y la acción. El descubrimiento de otra racionalidad.

La concepción tradicional de la técnica como conjunto de medios viene de Aristóteles. En sí misma, la técnica carecía de sentido, era neutral. No podía ser de otra manera en tanto que medio para cumplir fines humanos. La validez de la técnica no dependía de metas técnicas. Sus resultados no podían ser necesarios ni lineales. El sentido de la producción técnica se fundamentaba en designios humanos. ${ }^{7}$

La técnica sirve al bienestar humano porque es una proyección de la sabiduría práctica y se subordina a la actividad intelectual y a los postulados morales. La concepción aristotélica apenas ha encontrado oposición en la tradición filosófica. Pero Ellul ha demostrado que esa aproximación instrumentalista a la técnica no sólo resulta insuficiente sino que es, desde la óptica histórica y sociológica, del todo inexacta. La técnica ha levantado un nuevo orden. Merton ha comprendido que la técnica es mucho más que un haz de instrumentos: la técnica es todo un conjunto de medios que llevan a resultados predeterminados. Por lo que es capaz de convertir, señala Merton, el comportamiento espontáneo y no calculado en deliberated and rationalized. El hombre técnico siente verdadera veneración por los resultados inmediatos y tangibles. The Technical Man es un específico tipo humano que resulta del cálculo de medios y fines. La técnica se encarna en el hombre técnico y emprende el camino hacia la absoluta perfección, the one best way. La técnica es un fenómeno. ${ }^{8}$

En la concepción heideggeriana de la filosofía de la técnica, la cultura industrial contemporánea es un orden de medios -más allá de la moral-y de eficiencia tecnocrática, una tecnocultura, el fenómeno más opuesto a la emoción religiosa. Con una orientación inspirada en la aristotélica, Heidegger quiso establecer la relación entre la civilización técnica occidental y sus orígenes griegos: las manifestaciones técnicas de la modernidad llevan a una situación extrema la tradicional dualidad de medios y fines. Estos últimos han escapado al control humano. Pero la epistemología aristotélica era falsa y su filosofía social había quebrado. Se 
hacía perentoria una crítica sistemática que el paradigma instrumentalista ya no podía satisfacer. En la perspectiva heideggeriana, la concepción instrumentalista es una variante subjetivista. Tanto las aproximaciones instrumentalistas -la técnica como un conjunto de medios- como las propiamente antropológico-subjetivistas, la técnica como una actividad humana- presuponen una determinación humana de los fines y reflejan el dualismo sujeto/objeto de la definición aristotélica. ${ }^{9}$ Si la teoría aristotélica es instrumentalista, la de Heidegger es sustantiva. ${ }^{10}$ En cualquier caso, la concepción aristotélica de la técnica sigue siendo la dominante en la actualidad, a pesar de los intentos de reconstrucción de una filosofía ontológica de la técnica por parte de autores de tanto prestigio como Jean Baudrillard, David Lovekin o Arnold Pacey, entre otros. La mejor aportación de Heidegger a la filosofía de la técnica viene por vía de la aplicación del método fenomenológico desarrollado, después, por Ihde, ${ }^{11}$ entre otros. La técnica, para Heidegger, presenta una naturaleza ontológica. Los hombres no han sabido dejarla a su externo sino que, más bien, afirma su presencia en los rincones más íntimos de la existencia humana.

El enfoque tradicional hace equivalente a la técnica con el mundo de los artefactos, reduciendo el conjunto técnico a la categoría de objeto. Para Heidegger, la técnica es un proceso cultural por el que la existencia humana va estableciéndose en relación con la realidad natural. No puede considerarse, la técnica, como una aplicación de la ciencia, sino como un procedimiento artístico de construcción social. La técnica no es ciencia, sino arte. Un fenómeno poiético. ¿Cómo puede pensarse, la técnica, ontológicamente? Siguiendo a Heidegger, su implicación existencial encuentra su fundamento en un interés humano. El sentido de la técnica no reside en la satisfacción de necesidades humanas, sino en el interés de la especie humana en el Ser de entidades específicas y finitas. La actividad técnica es una respuesta a la finitud. ${ }^{12}$ Y la respuesta humana a la técnica es muy limitada. La verdad técnica es lo que Heidegger llama Gestell -a estos efectos, de un alcance similar al conocimiento tácito de Michael Polanyi, apunta Christians. ${ }^{13}$ La técnica emerge ontológicamente en una estructura que debe ser continuamente reforzada como condición de supervivencia. El dominio de la técnica se refuerza sin cesar en los procesos de socialización. Los nuevos tiempos del Ser son técnicos. Pero Heidegger no es determinista, aunque rechace la presunción de que la libertad humana sea independiente de la necesidad técnica. «Al revés que el primitivo, antes de inventar (el hombre) sabe que puede inventar; esto equivale a que antes de tener una técnica tiene la (en cursiva en el original) técnica. Hasta ese punto y aun en este sentido casi material, es cierto lo que vengo sosteniendo: que las técnicas son sólo concreciones a posteriori de la función general técnica del hombre.. ${ }^{14}$

La relevancia establecida de la impronta técnica ha suscitado múltiples respuestas desde distintos enfoques de la filosofía de la técnica. Así, para hacer frente a los problemas «tecnosociales», abundan las explicaciones analíticas de «riesgos/costes/beneficios», ${ }^{15}$ en líneas similares a la adoptada por el enfoque de 
Technology Assessment. ${ }^{16}$ No hay fatalidad en el cambio tecnológico. Ni su ritmo ni su dirección han sido predeterminados. «Es un proceso en el que los individuos y los grupos sociales tienden a su readaptación, exclusivamente, utilizando el cambio técnico y la tecnología misma y constituyendo un proceso social en el que los individuos y las colectividades hacen sus propias elecciones. Esta es la tesis de Salomon.» $\rangle^{17}$ Ellul apunta que tales elecciones sociales no son expresivas de libres voluntades, ni siquiera de valores sociales, sino solamente de otras obligaciones que el hombre no puede evitar. En cualquier caso, Salomon, dice Ellul, presenta un programa para «la desacralización de Prometeo» y se felicita de que haya instituciones cuyo papel sea el de la evaluación de las técnicas, atendiendo tanto a las consecuencias económicas como a las sociales. Y propone la uniformización de la educación de manera que no haya diferencias entre los que se muevan bien en el plano tecnocientífico y los que no puedan hacerlo. Así, Salomon sostiene que hay que ver, en la tecnología, no el dominio reservado a los técnicos, sino un proceso social que ya no puede escapar al control de todos los grupos sociales. Por su parte, Scardigli también presenta sus hipótesis acerca de la libertad de elección y la capacidad humanas de control de la técnica. En nuestro mundo, dice, la persona deviene la célula social de base. ${ }^{18}$ Piensa Scardigli que estamos a tiempo de culminar con éxito un esfuerzo de reapropiación de las técnicas gracias a la formación y la educación, con las que podríamos beneficiarnos de una tecnología de segundo grado, cuya perfección consistiría en hacer sencillo el acceso a tecnologías cada vez más complejas. Se trataría de un conjunto de tecnologías de facilitación, que permitirían la apertura de los saberes y el establecimiento del contacto con los demás, es decir, el impulso de la comunicación. En lo sucesivo, dispondremos de una verdadera tecnología de lo cotidiano que hará posible la reapropiación de una parcela de poder, la que ocupa la técnica, dice Scardigli: la afirmación colectiva de la diversidad, la conquista personal de la autonomía, el consecuente saber reencontrado, sería «poder escoger». Así, por ejemplo, la técnica comporta un poder de homogeneización, pero el consumidor encuentra ventajas evidentes: las nuevas técnicas de comunicación deben someterse a la opinión del usuario, que procederá a la evaluación de sus contenidos y «nadie podrá obligarnos a usar el teléfono o a ver la televisión, o simplemente, volver a la naturaleza.» Salomon y Scardigli parten, en las obras referidas, de una mera descripción de las amenazas de las técnicas, del poder que pueden lanzar contra el hombre y la sociedad, de la solidez de su desarrollo. Pero, a continuación, en términos de Ellul, «dan un salto y se inscriben de lleno en un acto de fe, en una suerte de metafísica.» ${ }^{19}$ Los ensayos de Salomon y Scardigli se inscriben, pues, en la línea de lo que en los años 60 y 70 vino en denominarse el technology assessment, que consistía en lo sustancial en programas de identificación de los intereses potenciales de las aplicaciones de la investigación y la tecnología. Se trataba de proponer medios para ponerlos en acto, de identificar los efectos secundarios y perversos de tales realizaciones técnicas antes de que sus consecuencias 
se volvieran irreversibles, de informar al público de los eventuales efectos de las aplicaciones técnicas y de tomar las medidas necesarias para su eliminación. Esos eran los objetivos. Y los principios de acción también son conocidos: los errores resultan de la ignorancia en el ámbito de las aplicaciones científicas, técnicas y sociales. Así pues, el poder para la decisión debe ser equitativamente repartido entre todos los ciudadanos. A partir de esos magníficos proyectos, se desarrollaron debates, discusiones y llegaron a crearse, incluso, centros de estudio e investigación al respecto. Pero, en el transcurso de los debates, el proyecto fue perdiendo ambición hasta orientarse, de hecho, hacia la potenciación del crecimiento de la investigación y el desarrollo, concluye Ellul. Pero, sobre todo, el de technology assessment es un proceso de autojustificación, una operación de opinión pública. No es más que una versión renovada, sentencia, de «la escuela de las relaciones humanas," el sistema de relaciones públicas del sistema técnico. Y desde que existe, nunca ha logrado el menor control efectivo, la mínima reducción de una iniciativa técnica en razón de sus riesgos. $\aleph^{20}$

En la posición opuesta, desarrollando una suerte de neokantiano imperativo categórico de prudencia ante las innovaciones tecnológicas que pudieran asentar una «edad técnica», se sitúa el filósofo alemán Hans Jonas. ${ }^{21}$ Por otro lado, un heideggeriano, Daniel Dahlstrom, sostiene que la técnica es, sobre todo, un medio de supervivencia que se ha convertido en una especie de rito expresivo del triunfo de la especie humana..$^{22}$ Y para Albert Borgmann, heideggeriano también, la esencia fenomenológica del tiempo de la técnica es el device paradigm, la proliferación de artefactos que contribuyen o no a traer la «vida buena». ${ }^{23}$

Por otro lado, según Arnold Toynbee, dejamos atrás el período técnico para entrar en el de la organización. Ya no es el orden mecánico, afirma el ilustre historiador británico, el que caracteriza nuestro mundo, sino el que James Burnham describe, de forma magistral, acepta Ellul, en su Managerial Revolution. Sólo que, aduce Ellul, (en La Technique...) a la propuesta de Toynbee, que la separación entre una era técnica y una era de la organización implica una reducción inscrita en los términos de la confusión entre la mecánica y la técnica. Pero no hay mayores problemas que impidan aceptar las teorías de Toynbee y Burnham. ${ }^{24} \mathrm{Al}$ respecto, a través de aproximaciones distintas a la elluliana vienen a decir que nuestro tiempo es el de la técnica aplicada a la vida social, económica o administrativa. Lo que conduce a la estandarización y racionalización de los ámbitos de implicación. Se trata, sobre todo, de anticiparse a las consecuencias de la acción por medio de procedimientos aplicables a casi todos los efectos. «La impersonalidad» va de suyo. Mientras, para Toynbee, la organización abre la vía de las soluciones para el progreso, insiste Ellul en que el desarrollo organizacional «aumenta, de por sí, los problemas técnicos, dando soluciones parciales a viejos problemas, pero escogiendo deliberadamente el camino que los había provocado. Se trata del célebre método que consiste en hacer un hoyo para tapar el de al lado. $\rangle^{25}$ Pero entre Toynbee y Ellul se muestra otro desacuerdo más: para el primero, los efectos de la organización serían previsibles; para el segundo, 
la imprevisibilidad de sus efectos es constitutiva de la organización.

Por su parte, Marcel Mauss elaboró una definición descriptiva de la técnica, válida únicamente para las sociedades primitivas. Para Mauss, la técnica es un grupo de movimientos, generalmente actos, casi todos manuales, organizados y tradicionales, tendentes a la obtención de un objetivo físico, químico u orgánico. ${ }^{26}$ Pero, ante todo, las técnicas son «hechos de civilización,»en términos de Mauss. En la actualidad, comprobamos una y otra vez que las técnicas exceden los dominios de la física o la química. «El psicoanálisis y la sociología dan un salto al ámbito de las aplicaciones, por ejemplo, la propaganda. (En este supuesto, la operación técnica es de carácter moral, psíquico y espiritual.) Pero se trataba de un mundo envuelto, hasta entonces, en el pragmatismo y se acercó rápidamente al método.» ${ }^{27}$

Para Jean Fourastié, la técnica sólo es un conjunto de medios que permite la economía de materias primas o trabajo humano. ${ }^{28}$ Pero es una noción arbitraria, que no toma en cuenta el grandísimo número de técnicas que no persiguen un rendimiento económico. Por ejemplo, las descritas por Mauss. Pero, por lo mismo, la noción de técnica unida a la de productividad tampoco puede sostenerse, en tanto la productividad implica una reducción de la noción de rendimiento. Es más, las técnicas que conocen un desarrollo más intenso son las aplicables a las personas (por ejemplo, las «reingenierías») y, precisamente, las encaminadas a la búsqueda de resultados destructivos (por ejemplo, las de guerra.) Late una relación orgánica entre el progreso técnico y la guerra, sospecha Ellul. Y no únicamente a causa de la presencia directa de la técnica en los medios destructivos, sino también a causa de la influencia técnica en los entornos existenciales. «El progreso técnico propicia la guerra porque: «1. las nuevas armas hacen más difícil la separación entre agresión y defensa; 2. las nuevas armas han reducido extraordinariamente el dolor y la angustia que implica el arte de matar. ${ }^{29}$ Sería absurdo distinguir la industria pacífica de la militar. Por pacíficas que sean sus intenciones, cualquier operación industrial es susceptible de aplicaciones bélicas.

Incluso Georges Friedmann tiende a la reducción del problema de la técnica a las dimensiones de las técnicas de producción económica, ${ }^{30}$ apunta Ellul. Y Harold D. Lasswell define la técnica como «el conjunto de prácticas de las que se sirven los

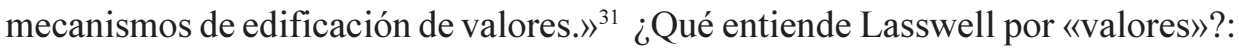
la riqueza, el poder, el bienestar... ¿Y por «prácticas?: las técnicas de gobierno, producción, etc. Su definición de técnica es un corolario de sus prenociones técnicas, las facilitadoras de tan peculiares valores.

Para llegar a una definición plausible de la técnica, hay que distinguir previamente la operación técnica (1) del fenómeno técnico (2). (1) Es la actividad que recurre a un método para lograr un resultado: «sólo es un procedimiento perfeccionado gracias a un progreso científico que distingue a la operación técnica moderna respecto de la primitiva. $)^{32}$ Lo característico de la operación técnica es la búsqueda incansable de mayores cotas de eficacia. (2) El fenómeno técnico es el 
resultado de una doble intervención en el marco extenso de la operación técnica: la de la conciencia y la de la razón. La razón arrumba los saberes por experiencia y crea métodos nuevos mediante la experimentación, con lo cual actúa a la manera de multiplicador de las posibilidades de las operaciones técnicas con miras al logro de resultados, por vía del hallazgo del medio más eficiente. La conciencia técnica, por su parte, es el fruto de la asunción de las posibilidades de la técnica, lo que, a su vez, permite su extensión a casi todos los campos de actividad. ${ }^{33}$ El fenómeno técnico es el one best way.

La técnica se ha convertido en el lenguaje universal, «por compensación y por necesidad.» Es un resultado de la especialización rampante que, en sí misma, es ya un gran obstáculo para la comunicación y la cooperación: «...la especialización ha roto el cordón umbilical que unía a los hombres entre sí, y con la naturaleza..» ${ }^{34}$ Ya no es, únicamente, un problema de vocabulario y dominio de un sabercohabitando-con-la-ignorancia, sino de la extrema dificultad de comprensión de las razones profundas del otro, del no idéntico a uno mismo. Pero la propia técnica, que provocó la ruptura, establece mecanismos de comunicación entre las diversas especialidades. Tales mecanismos se subsumen en ella misma. La técnica equivale a la razón profunda universal, un nuevo absoluto.

Lo mejor es siempre lo nuevo. Esta ley de hierro del progreso técnico es de naturaleza metafísica. Lo que puede hacerse, debe hacerse. Toda una declaración de principios: la técnica oscurece el sentido de lo trascendente y establece medios específicos para fines específicos (cuando los haya). Un conjunto de medios y fines, que forman un continuo sin límites ni clausura. Un mundo cartesiano, pues. «Desde este punto de vista, podría decirse que la técnica es la traducción del sueño humano de dominar las cosas a través de la razón. Hacer cuantificable lo que es subconsciente, cuantitativo lo que es cualitativo, rodear de un gran trazo negro los contornos de la luz proyectada en el tumulto de la naturaleza, actuar sobre el caos y poner orden..$\rangle^{35}$

La técnica es, ahora, un poder sin freno, aunque exista una especie de resistencia que se debilita gradualmente. Fuerzas diversas intervienen en ese acontecimiento. En primer lugar, la moral. En segundo lugar, la opinión pública, que presenta un comportamiento mucho más irracional y no se deduce, forzosamente, del bien o el mal. La opinión pública se inclina, por su cuenta, hacia un extremo u otro: o se comporta de manera refractaria a determinados impulsos por razones todavía poco determinadas, o se deja llevar pacíficamente por aquéllos. Evidentemente, la opinión pública desempeña un papel decisivo en la relación que aparece entre los hechos de nuevo cuño y la moral establecida, en tanto puede llevar al fracaso de la moral o, por el contrario, inclinarse a su favor y hacerla triunfar. Y, en tercer lugar, la estructura social, trátese de la morfología social o la estructura jurídica o económica. Esta última actúa de manera decisiva cuando circunstancias nuevas parecen modificar lo establecido. Es, dice Ellul, el único hecho esencial que el marxismo, fundiendo economía y técnica, considera 
determinante, al respecto. No se trataría, únicamente, de los sistemas o las ideas, sino sobre todo de las relaciones económicas o de factores sociales que pudieran cambiar una situación que se había considerado sólidamente establecida. ¿Cuál es la situación actual, se pregunta Ellul, en lo que concierne a la técnica? Propone Ellul: dejemos de lado el problema de la moral, puesto que conviene evitar el recurso a las proposiciones axiológicas. En cuanto a la opinión pública, cabe señalar que se orienta por entero en favor de la técnica. Y es que lo único que interesa al hombre actual es el mundo de los hechos técnicos. La máquina ha conquistado el cerebro y el corazón del hombre medio, de la masa, que, por su lado, se muestra apasionada por la performance. La opinión pública emprende una doble dirección: 1) Por una parte, la de la adoración de los poderes de hecho, desplegados en todas las técnicas y expresados en la consagración total de los individuos a ese imparable avance; no se trata de una adoración pasiva ni mucho menos «mística». 2) Por otra, internaliza la convicción de que los problemas técnicos son los únicos serios y pertinentes. La mirada despectiva, cuando no agresiva, ante la filosofía, la falta de interés ante las cuestiones metafísicas o teológicas, el rechazo de las humanidades, la búsqueda de lo que «sirve», son signos de esa racional convicción que afecta a todos los escalones de la jerarquía social. Se trata de un comportamiento idéntico a todas las clases sociales. Así, la opinión pública puede orientarse en un sentido del todo favorable a la técnica. Y, por lo que respecta a la estructura social, la vida del mundo moderno se muestra cada vez más dominada por la economía y ésta, por la técnica. El mundo material se asienta sobre una base técnica, concluye Ellul en La Technique...

Con todo, la concepción de la técnica que subyace el optimismo prometeico de Occidente desde hace muchos siglos se mantiene en nuestros días. Y se identifica con la sociedad burguesa, anclada en la economía de mercado y la producción de bienes de consumo. De suerte que durante mucho tiempo se ha podido contemplar el progreso técnico como la forma de expresión de un dominio del hombre sobre la naturaleza y las cosas gracias a la acumulación de saberes científicos. Hoy, asociada a la ciencia, la técnica permite igualmente una acción intencional, directa y eficaz sobre los seres humanos. Los medios de acción de las técnicas aplicables a los hombres responden a los criterios de generalidad, objetividad y permanencia. Se trata de encontrar el medio más eficaz para lograr el resultado perseguido. Cuando Serge Tchakotine ${ }^{36}$ escribe que la comprensión de los mecanismos de comportamiento entraña la posibilidad de manipular nuestra voluntad y, por ello, es posible calcular, prever y actuar según reglas controlables, dice Ellul, describe exactamente, hablando de la propaganda, los caracteres habituales de la técnica. Y tres hechos consumados, insiste Ellul, manifiesta esa realidad: a) La actitud corriente de los hombres que aplican tales técnicas, que escogen, entre los datos científicos, aquellos que parecen utilizables, y adoptan una cierta condescendencia desdeñosa hacia lo que no «sirve». Proceden, pues, a indispensables simplificaciones para tal o cual aplicación. b) La intervención de las matemáticas, la biometría, la psicometría, 
la sociometría o la cibernética ha de sufrir el trayecto ineludible para el perfeccionamiento de las técnicas aplicadas. Resulta ilusorio considerar, en efecto, que a partir de leyes no mensurables, a partir de observaciones no cuantificables, pueda construirse un verdadero sistema de acción. Así, cuando se trata de hacer propaganda, hay que recurrir a conocimientos exactos. Siempre hace falta la exactitud matemática; únicamente los métodos métricos pueden analizar y prever el recorrido de una acción eficaz. ${ }^{37} \mathrm{Y}$ produce perplejidad que los métodos métricos, aplicados en escenarios políticos distintos, desemboquen en los mismos resultados. Quizá podría entresacarse, de esa circunstancia, una característica de las técnicas; y cita Ellul a Paul H. Maucorps, ${ }^{38}$ que, en su estudio de la sociometría americana, llega a las mismas conclusiones prácticas que el stajanovismo. Y Rubistein, añade Ellul, llega, desde el punto de vista soviético, a los mismos resultados. c) El «espíritu de experimentación técnica»: se trata de aplicar, a los conjuntos humanos, medios técnicos eficaces dirigidos tanto al individuo aislado como al hombre social, al joven y al adulto, a la voluntad, o a ese lugar indiscernible en el que la materia deviene espíritu, concluye Ellul. Conviene coordinar tales técnicas a modo de sistema porque, en esos sistemas ya formados, una misma técnica podrá aplicarse varias veces en planos diferentes y con objetivos diferentes. «Bien es verdad que la educación, la política, son también técnicas; pero conviene recuperar la distinción entre las técnicas primitivas y pragmáticas y el fenómeno técnico: lo nuevo es el hecho del cálculo, de la sistematización y la conciencia; las técnicas que usurpan el espacio de la acción espontánea son deliberadas, aplicadas en tanto que técnicas, y es esto lo que rompe el antiguo orden relacional..» ${ }^{39}$

\section{LA RELACIÓN ENTRE LA CIENCIA Y LA TÉCNICA}

Se acepta pacíficamente que la técnica sea una aplicación de la ciencia. Si ésta fuera pura especulación, la técnica se presentaría como el punto de contacto entre la realidad material y la conclusión científica, entendida como el resultado experimental, como la prueba de realidad, la aplicación de la ciencia a la «práctica». La ciencia pura abre el camino a una ciencia aplicada que potencia, a su vez, efectos técnicos que impulsan los saberes puros en una determinada dirección. Este último supuesto puede constatarse, especialmente, en el ámbito propio del saber de la economía política. Esta visión tradicional de la relación entre la ciencia y la técnica es radicalmente falsa, sostiene Ellul. No es más que un residuo de una categorización de los saberes científicos que tuvo sentido en el siglo XIX y para el ámbito específico de las ciencias naturales.

La realidad de la relación histórica entre la ciencia y la técnica desmiente la concepción tradicional, dominante aún, incluso en nuestros días, en la comunidad científica. Al contrario de lo que suele aceptarse, la técnica es cronológicamente anterior a la ciencia. Así, las técnicas helenísticas no se desprenden de la «ciencia 
griega». Pero la cuestión esencial radica en los distintos niveles de interacción entre una y otra: «La investigación científica requiere, hoy, un enorme utillaje técnico.(...) Y muy a menudo, una simple modificación técnica permite un progreso científico. $\rangle^{40}$ Y presenta Ellul los ejemplos de las investigaciones de Faraday sobre los constituyentes de la materia y el descubrimiento de la penicilina, a modo de ilustración, no demostración, claro está, de su conjetura.

Este es el esquema que aparece en La Technique... En Le Système technicien, Ellul se empeña en demostrar la inexactitud de esa proposición que afirma que la ciencia pura lleva a la ciencia aplicada y la ciencia aplicada lleva a la técnica. Y en Le Bluff technologique, describe la interacción entre la ciencia y la técnica con un prurito de actualidad, al modo de La Technique... Esto es, la ciencia no podría progresar sin el concurso decisivo de la técnica, trátese de las estructuras moleculares, los desarrollos químicos, la propia matemática, (sin perjuicio de su naturaleza no científica, en sentido estricto, según las condiciones de los objetos de conocimiento científico del paradigma de las ciencias naturales) o el estudio de la inflación. Es más: los progresos científicos dependen, por entero, sentencia Ellul, de los equipamientos técnicos, aunque no superen el estatuto de condición necesaria pero no suficiente. El prestigio de la ciencia es función del progreso técnico. Y, por supuesto, el progreso técnico no sería posible sin el de la ciencia. ${ }^{41}$ Esta es una norma que afecta incluso a los saberes aparentemente alejados del fenómeno técnico, como, por ejemplo, la lingüística, que colabora al progreso de la técnica a través de los descubrimientos de lenguajes que permiten la comunicación directa entre los hombres y los ordenadores. Del mismo modo, el saber analítico abre el camino a los sistemas expertos. Así, el círculo se cierra: la ciencia acelera el progreso técnico y éste retroactúa sobre la ciencia propiciando nuevos descubrimientos. ${ }^{42}$ Es más, importantes parcelas del progreso técnico ya no encuentran otra aplicación ni utilidad que las de sus posibles aportaciones al desarrollo científico. En tanto la ciencia constituya la justificación última de nuestro mundo, los recursos destinados al desarrollo técnico se legitimarán por sí mismos. ${ }^{43}$ Además, lo habitual es que las técnicas se apliquen en el plazo más inmediato posible. El mercado y el Estado protagonizan ese interés. «Y el científico se ve obligado a aceptar sus condiciones.» Hasta el extremo de que, en términos de Mauss, «la ciencia, (...) se ha convertido en un elemento de la técnica, un medio.. ${ }^{44}$

Por otro lado, constata Ellul la generalización, a casi todas las esferas sociales, de una «actitud científica: no puede conocerse más que lo que sea cuantificable... $\rangle^{45}$ Se trata de sortear las aproximaciones arbitrarias y subjetivas, propias del juicio estético o literario. El método por excelencia es el que se nutre de los modelos matemáticos. También la técnica se ve reducida a esos extremos. La originalidad de la técnica viene de su incansable búsqueda de la eficacia a partir del cálculo de medios y fines, «toda una ciencia de los medios, una ciencia de las técnicas progresivamente elaborada. $»^{46}$ Es lógico que así sea. Ninguna actividad 
humana se libra de aquel imperativo técnico. Asimismo, el designio de la acumulación de conocimientos no podía resistir un tipo de investigación basado en la experiencia «individual, artesana, sino (en la experimentación) de orden abstracto, matemático e industrial,,${ }^{47}$ pero armónica y amable con la potenciación del hálito individual y privativo.

Mientras la ciencia trata de explicar racionalmente los hechos y fenómenos, la técnica busca la evidencia a través de la aplicación, de la acción. Mientras la ciencia supera lo que un día fue sagrado, la técnica lo subsume y lo sagrado «no puede resistirse». «La ciencia nada hasta el fondo del mar para fotografiar las formas de vida desconocida que puebla los abismos, la técnica los captura y las traslada a la superficie para comprobar si son comestibles... $\rangle^{48}$ No puede aceptar Winner, por todos, que la técnica devenga autónoma, ni puede mostrarse conforme con la supuesta identificación elluliana de la ciencia y la técnica, ${ }^{49}$ cuestión que no ha comprendido el sociólogo americano. Hubiera bastado la lectura de las primeras páginas de $L a$ Technique..., para comprobar que Ellul no sólo no confunde la ciencia y la técnica sino que, a las alturas de nuestro tiempo, las separa a una distancia de años-luz.

\section{CARACTERÍSTICAS CONSTITUTIVAS DEL FENÓMENO TÉCNICO}

Las características comunes a las técnicas encuentran su síntesis en el fenómeno técnico. No obstante, este nuevo principio de dominio muestra una complejidad mayor de la que pudiera revelar el análisis de tales características que, eso sí, puede arrojar luz sobre la verdadera naturaleza de la técnica.

Así, hasta el siglo XVIII, la técnica no evolucionó de manera autónoma, sino en estrecha relación con muchos otros factores y, a menudo, de carácter privativo para la sociedad de que se tratara. De manera que «casi nunca encontramos (en la historia) una técnica en estado puro.» ${ }^{50}$ Según los lugares, las técnicas presentaban múltiples variaciones, aunque fueran sus fines los mismos para todos. Pero cuanto más progresaban las técnicas, más visible se hacía otra causa de diversificación: la perfecta adaptación, condición de eficacia. «Ahora bien, el instrumento más racional no repara en la extrema diversidad natural. En realidad, (la diversidad) es, incluso, una característica esencial de la técnica. Cada procedimiento condiciona un específico resultado, uno nada más. $\rangle^{51}$ Esa diversificación se agudiza según la especialización que se exige de los útiles técnicos. En el siglo XVIII, los hombres aún podían controlar la situación. Al menos, tenían capacidad de elegir una forma contemplativa de vida. Pero el siglo XIX trajo una «interacción de la eficacia técnica y la decisión humana eficaz... $\rangle^{52}$ El prestigio de la técnica se extiende con celeridad. La objetivación de la técnica permite la apertura de un nuevo tipo de universalidad. Las técnicas dispersas han muerto. Emerge el todopoderoso fenómeno técnico. Y nada tiene que ver con el pasado de la técnica. La causa eficiente de tal novedad es la ausencia de límites para la técnica, que se extiende a todas las esferas y a todas las actividades En efecto, el desarrollo de la técnica conduce a una multiplicación 
sin límites de los medios, perfeccionando indefinidamente los instrumentos de los que puede servirse el hombre, poniendo a su disposición una variedad casi indescriptible de mediadores y auxiliares. Y esta técnica, devenida perfectamente objetiva, que se transmite como una cosa, independientemente de las circunstancias del entorno, conduce a la unidad de la civilización. He aquí, pues, la negación de la correspondencia entre la técnica actual y la tradicional. Las nuevas características de la técnica son las siguientes:

1) «La racionalidad», que implica, en primer lugar, una doble intervención: «la de una reflexión voluntaria... (y) la de mediaciones.» Y, en segundo lugar, «la reducción a un discurso» que responde a una dimensión monológica. ${ }^{53}$

2) «La artificialidad.» La acumulación de medios técnicos construye un mundo artificial, radicalmente distinto al natural, «...por lo que la comparación, propuesta por Mounier, entre la máquina y el cuerpo humano, carece de valor. $\rangle^{54}$

A estas características añade Ellul otras, que son, precisamente, las que dan carta de naturaleza propia a la técnica de nuestros días:

3) «La naturaleza automática de la opción técnica.» Los hombres escogen, únicamente, la operación que logre la máxima eficiencia. Al interno del mundo técnico, la elección entre los procedimientos y los procesos es automática. Y aún más: la operación técnica desplaza cualquier actividad extraña a la técnica o simplemente la transforma. Si los hombres deciden escoger un medio tradicional, o algún otro fruto de su ingenio personal, o se dejan llevar por principios morales ajenos a la servidumbre respecto de los resultados, tendrán que aceptar un grado inferior de eficiencia y, por tanto, temblarán sus probabilidades de éxito. Las oportunidades sociales y las de mercado dependen de la técnica. Sólo un poder técnico puede oponerse a otro poder técnico. La técnica es consciente de su perfectibilidad y emprende el camino de la optimización.

4) «El autocrecimiento», que, a su vez, muestra una doble vertiente: a) El desarrollo de la técnica exige cada vez más invenciones, más materias primas y mayor complejidad técnica. Se produce un crecimiento no calculado, automático. «En realidad, la técnica se engendra a ella misma. $\rangle^{55}$ Pero se apresura Ellul a señalar que el autocrecimiento no implica, necesariamente, un desarrollo infinito e indefinido de la técnica. b) Por otra parte, el autocrecimiento es una consecuencia del principio de combinación de las técnicas. Las innovaciones técnicas impulsan otras innovaciones técnicas muy variadas y para ámbitos distintos. Nunca se detienen ni, menos todavía, retroceden. Progresan geométricamente, gracias a sus múltiples combinaciones. Algo que, por cierto, presenta un especial interés para la sociología de las desigualdades sociales, por más que parezca un tanto desconcertante: el autocrecimiento es desigual y propicia la desigualdad social.

5) «La unicidad.» Los hombres no necesitan conocer los principios técnicos para aprovecharse de ellos. En realidad, ningún técnico domina el conjunto de las técnicas. Y son sus leyes internas las que coordinan y racionalizan, de modo creciente, 
las relaciones sociales. De hecho, «el obrero no puede comprender el funcionamiento de la industria moderna», afirma Charles Camichel. ${ }^{56}$ Sólo la unicidad intrínseca de la técnica asegura la cohesión entre los medios y la acción social. El fenómeno técnico constituye una totalidad y presenta, en lo esencial, las mismas características aunque concierna a esferas muy distintas: «... en el fenómeno técnico (...) todos los elementos están ontológicamente ligados.... $\rangle^{57}$ Un conjunto en cuya virtud los hombres se adaptan al principio mecánico de acción, sin perjuicio de la necesaria diferenciación entre la oportunidad del medio aislado y la del «complejo mecánico».

6) «La imprevisibilidad». Nadie podrá discutir la necesidad urgente y universal de la previsión. Todas las instituciones económicas, políticas, sociales y militares se apoyan en los cálculos de estrategia y en las probabilidades de acción. Resulta difícil de imaginar una realidad social independiente de las representaciones, las anticipaciones, las predicciones, etc. ${ }^{58}$ Incluso, como es de sobra conocido, una representación puede volverse real por el mero hecho de que las acciones y reacciones engendradas por ella misma le otorguen el estatuto de realidad. En este sentido, Merton pudo describir y explicar el fenómeno de las consecuencias no anticipadas de las acciones sociales intencionales, esto es, lo que ha venido denominándose «la profecía que se cumple a sí misma» (self full filling prophecy ${ }^{59}$.) En un sistema liberal, la necesidad de la previsión es fundamental, la condición que requiere «la mano invisible» de Adam Smith. Pero también es la condición del tránsito del orden individual al orden colectivo, advierte Ellul. Con mayor precisión: aquello que Hayek (el ilustre economista distinguía tres categorías de fenómenos sociales: los puramente naturales, independientes, pues, de la acción humana; los puramente artificiales, producidos por un deseo humano; y los intermedios, que comprenderían las configuraciones e irregularidades no intencionales que aparecen en las agrupaciones sociales y que correspondía explicar a la teoría social) identificó como «categoría intermedia». Habrá que contar, propone Ellul, con esos «órdenes espontáneos», vale decir, con los resultados de la acción no correspondientes a la intención. La imprevisibilidad técnica no puede atender a «la eventualidad de una guerra atómica o a la eventualidad de una revuelta generalizada del Tercer Mundo o de un crecimiento exponencial del desempleo o de una quiebra financiera generalizada..${ }^{60} \mathrm{El}$ discurso de la técnica se fundamenta en la creencia de que el hombre es el dueño y señor de la técnica, que, por su parte, no sería más que un instrumento pasivo. El hombre es su creador, la conoce perfectamente y puede utilizarla a su voluntad. Así, un ordenador no hará nunca más que aquello para lo que fue programado, salvo accidentes, advierte Ellul. Ahora bien, esos accidentes constituyen un supuesto, reconoce Ellul, en el que la técnica «representada por sus ingenios, ha escapado al control del hombre, pues aunque sea a estos niveles podemos afirmar que el hombre no siempre controla a la técnica y en tanto aumente su poder, las carencias de control humano serán, a la vez, más graves y numerosas..$\rangle^{61}$

La previsión resulta indispensable a todos los efectos y aún más cuando el 
sistema se organiza en torno a una fuerte estatalización, con una omnipresente administración, un Estado-providencia y una economía planificada. La búsqueda de los métodos más eficaces para garantizar los aciertos de las previsiones se explica por sí misma. Al respecto, desechado, por fin, el método de la extrapolación lineal, la previsión se fundamenta en los saberes de la prospectiva y la futurología. En el primer caso, se recogen los datos susceptibles de previsión contemplándolos en términos de probabilidad, en una línea evolutiva. La prospectiva ha logrado monopolizar los saberes de la previsión. No se trata de una ciencia como tal, advierte Ellul, sino de una parcela del conocimiento científico que trata de fundamentar la acción actual en hipótesis atingentes al futuro. El objeto de ese saber requiere la evaluación en el largo plazo. Mientras la futurología consistía en el cálculo entre posibles, la prospectiva contempla la evolución más probable.

Ahora bien, los resultados nunca se compadecieron de las expectativas que llegaron a despertar los referidos saberes. ${ }^{62}$ De manera que la comunidad científica fijó su atención en los sistemas de los modelos (se procede a un análisis de la situación actual, se establecen los principales parámetros y se considera lo que debe suceder si adviene la variación de algún parámetro en un marco de estudio de todas las variaciones posibles de todos los parámetros.) Observa Ellul que difícilmente podría, el sistema de los modelos, convertirse en guía de acción. Así, mientras los futuribles se conformaban con el hallazgo de un «movimiento de previsión», los modelos tratan, incluso, de proponer objetivos, con lo que la prospectiva cubre una parte primera de una actuación total -la que señala lo que puede suceder-y los modelos establecen repertorios de objetivos probables. Ellul insiste en el fracaso rotundo de todos los métodos de previsión conocidos. ${ }^{63} \mathrm{Su}$ escaso rigor, que se proyecta, especialmente, en las previsiones económicas, conduce a Ellul a la doble cuestión de las nociones de imprevisión e imprevisibilidad. Hay imprevisión cuando se hubiera podido prever y no se hizo. Hay imprevisibilidad cuando se quiso prever y no se pudo. La primera afecta a todas las esferas, pero sobre todo a la económica, envuelta en una imprevisión de carácter global.

Si la previsión es indispensable pero imposible, sea por la dificultad de su objeto o por la intervención de ciertas tendencias, provengan de la mutación de la experiencia del tiempo o no, es preciso, propone Ellul, fijar la mirada en otra cualidad, «la prévoyance» (que no equivale a previsión aunque en castellano se traduzca también como «previsión».) La prévoyance, sugiere Ellul, podría ocupar la plaza de la previsión cuando fuera necesario (a menudo en una «civilización de riesgo». ${ }^{64}$ ) Consistiría, en lo esencial, en prepararse para lo peor como probable, pero no en virtud del cálculo de probabilidades sino de la propia experiencia humana.

Es imposible prever todas las consecuencias de una acción técnica. Esta proposición deductiva podría encontrar una difícil refutación en otras proposiciones inductivas que demostraran la previsibilidad de efectos de una determinada operación técnica, pero no para el conjunto técnico. En dirección 
opuesta, otras muchas proposiciones inductivas podrían demostrar la afluencia de efectos no deseados y, en cualquier caso, imprevisibles, aunque se manifestaran en ámbitos distintos al propio de la operación técnica de referencia. La imprevisibilidad es constitutiva e inmanente a la técnica.

Señala Ellul dos tipos de imprevisibilidad: la relativa y la absoluta. La primera se manifiesta ante un acontecimiento sobrevenido del que, razonablemente, no podía preverse su existencia o el momento de su aparición. Cuando adviene un fenómeno de esa naturaleza, se abren dos posibles orientaciones: o bien se recurre a medidas terriblemente drásticas y costosas o se desvía la mirada. Esa imprevisibilidad se proyectaría, incluso, en un cierto estado de los conocimientos que traería, a su vez, una gran incertidumbre, reducida, en la mayor parte de los supuestos, a la gestión de la incertidumbre y de los riesgos específicos. ${ }^{65} \mathrm{Y}$ a la imprevisibilidad relativa habrá que añadir la imprevisibilidad absoluta, aquélla que aparece cuando se observa la totalidad de los parámetros. No se trata de la propia de la invención científica, y ni siquiera de la imprevisibilidad accidental, sino de una irremediable, inherente al sistema técnico. Para comprender el alcance de la imprevisibilidad absoluta conviene tener en cuenta la presencia de cuatro factores decisivos: a) El primero fue objeto de un brillante análisis por parte de Edgar Morin: pensar correctamente el presente no es suficiente, dada la inevitable presencia de «gérmenes microscópicos invisibles», prestos a desarrollarse. Y es evidente que las innovaciones, las invenciones y las creaciones no pueden siquiera ser imaginadas antes de su aparición. ${ }^{66}$ Una innovación es, en principio, una desviación que deviene en tendencia y conforma una nueva regla de evolución: algo particularmente esencial en la técnica, asegura Ellul. b) El segundo factor de imprevisibilidad viene del mismo pensamiento técnico o, mejor, como dice E. Morin, «tecnoeconócrata». El pensamiento tecnoeconócrata piensa el mundo en términos de poder, de tasas de crecimiento, de PIB, de velocidad, de consumo, es decir, en términos de fenómenos secundarios. Es un pensamiento radicalmente incapaz de pensar la técnica en sí misma. En esa perspectiva, el pensamiento técnico deviene igualmente incapaz de prever lo verdaderamente nuevo. Simplemente, no va más allá de la reproducción y el perfeccionamiento de lo que ya existe. No podría pensar un nuevo paradigma, ni siquiera un acontecimiento imprevisto. c) El tercer factor de imprevisibilidad es el provocado por el riesgo inconmensurable de los riesgos asumidos y «de la especificidad de la nueva fase. $\aleph^{67} \mathrm{Y}$ d) Ellul añade la incertidumbre que resulta de un cambio relevante en el orden del pensamiento económico y sociológico. Lo propio de un mundo fluctuante, en estas circunstancias, es la práctica imposibilidad de dominio de la velocidad de los flujos de ideas, no siempre en buenas relaciones con la técnica.

7) «La ambivalencia». La experiencia histórica nos dice que los efectos del conjunto técnico suelen ser más dañinos que benefactores, afirma Ellul. Conviene recalcar: del conjunto técnico. Una mirada panorámica no podría llevar a otra conclusión. Sin perjuicio de la abundancia de supuestos particulares suficientes 
para mostrar ciertos grandes efectos benéficos para la humanidad. Así, el crecimiento demográfico, la prolongación de la esperanza de vida, o la disminución del tiempo de trabajo, «signos que, quizá, tendrían una significación si el hombre fuera un animal, pero que no resultan decisivos para un hombre que es algo más que una máquina de producción. $\rangle^{68}$ Pero no quiere afirmar Ellul que la técnica esté fatalmente abocada a la causación de catástrofes. La técnica es, al fin y al cabo, el efecto de un proceso de racionalización, de un principio de orden bien expresado en el desarrollo de las doctrinas morales y políticas de los primeros años del siglo XIX.

En cuanto a los efectos de la técnica, la opinión generalizada, casi unánime, sostiene que «la técnica no es mala; lo que ocurre es que el hombre la usa mal.» ${ }^{69}$ Esta opinión aparece estrechamente ligada a la frecuente confusión entre la máquina y la técnica. Quizá la máquina pueda usarse de una o otra manera, pero la técnica parece el medio más adecuado para hacer cualquier cosa, el único camino que lleva al máximo de eficacia en la acción. Una «mala» utilización invalidaría la propia esencia del fenómeno técnico. Y no referiría contenidos morales, sino del todo fácticos, positivos... O no sería técnica. De modo que la técnica y su aplicación conforman un todo. Una constitutiva unicidad. De ahí el principio técnico que Ellul define así: «el hombre se sitúa ante una elección excluyente, o bien usa la técnica como debe hacerlo, o no la utiliza; pero no es posible hacer uso de la técnica más que con arreglo a las leyes técnicas. $\rangle^{70}$ Pero las posiciones mayoritarias conciben la técnica de otro modo: puramente instrumental, impersonal, totalmente subordinada a la voluntad de la que es mediadora o amplificadora física, la técnica no es portadora de ninguna cualidad ética. Sin positividad propia, puede ser utilizada indiferentemente para el bien o el mal y deja totalmente libre al hombre en su relación con las cosas, con la sociedad y con los otros. ${ }^{71}$ No hay técnicas buenas y malas. Hay, simplemente, técnica. Es más: «cuando se dispone de un útil técnico, se aplica indefectiblemente, sin pensar si es bueno o malo. $\rangle^{72}$ Lo que puede hacerse, debe hacerse. Es la máxima de la acción técnica. Las controversias sobre la neutralidad de la técnica parecen de naturaleza perenne. En efecto, están presentes en todos los estudios sobre la génesis y el desarrollo de la racionalidad científico-técnica. La opinión mayoritaria insiste en que, per se, la técnica no es moral ni inmoral. Por lo tanto, su valoración moral ha de atender al uso y utilidad de cada recurso técnico. Así, para Samuel Florman, la técnica es neutral. Todo depende de su uso. Y mediante múltiples ejemplos de innovaciones tecnológicas quiere demostrar Florman el logro técnico de un contundente refuerzo de las relaciones convivenciales, que incluso permiten el establecimiento de estrechos lazos comunitarios salvando las distancias físicas. ${ }^{73}$

Pero la elección de fines «buenos» y el rechazo de fines «malos» en el uso de la técnica es una peligrosa ilusión. El fenómeno técnico no admite esa disociación: es único y cerrado. Las operaciones técnicas se combinan y conforman un conjunto coherente y coordinado, del que no podría desgajarse un elemento sin provocar la quiebra de todos los demás. Claro está que los efectos de la técnica en los grupos 
sociales no son siempre idénticos. «Los diversos fenómenos de asimilación, reagrupamiento, funcionamiento, marasmo o disolución progresiva son de sobra conocidos. $\rangle^{74}$ Advierte Cerezuelle que pensar que la naturaleza ética de la técnica depende de su uso -en relación a su provisión de efectos deseados y no deseados- es quimérico. Aún más, los problemas provocados por la técnica tienden a encontrar una solución técnica que abrirá nuevos problemas. Así, los fallos en las organizaciones se cubren con más organización, los de los artefactos con mejoras tecnológicas, etc.

8) «El universalismo», que adopta dos formas: la geográfica y la «cualitativa, podría decirse». ${ }^{75}$ Sea cual sea su grado de «civilización», todos los países adoptan y aplican los mismos procedimientos técnicos, aunque se sitúen en puntos distintos, según su nivel de desarrollo, de la trayectoria técnica. Y la técnica tiende a la uniformización de las culturas. En todas partes comporta los mismos efectos. Su fuerza expansiva procede de causas históricas, sobre todo la guerra y el comercio, señala Ellul. Pero, a partir de la Segunda Guerra Mundial, los factores de expansión se han visto favorecidos por la rapidez y la «intensidad» de los medios de comunicación y la movilidad geográfica de los técnicos, lo que debe implicar una cierta «unidad de formación intelectual». «En su relación con el mundo, el hombre siempre ha recurrido a multiples medios: ninguno era universal, porque ninguno era objetivo.» ${ }^{76}$ Pero la técnica propicia un principio de aprehensión de la realidad que sustituye, en la mente del hombre medio, a la comprensión en profundidad, lo que lleva al desplazamiento de las particularidades y la subjetividad. La técnica es indefectiblemente objetiva. Una mediación neutral entre «la realidad y el hombre abstracto»». ${ }^{77}$ Un modo de vivir juntos o, mejor, atados.

9) «La autonomía». Ellul encuentra un oportuno punto de partida, para la afirmación de su hipótesis de la autonomía de la técnica, en las aportaciones de Frederick Winslow Taylor. En efecto, para el impulsor de la organización científica del trabajo, la fábrica es un organismo cerrado, un objetivo per se. De acuerdo con la posición de Siegfried Giedion, infiere Ellul que esa clausura en torno al medio está a la base de la autonomía técnica. ${ }^{78}$ El desarrollo técnico exige esa condición de autonomía. «La técnica ha devenido autónoma y conforma un mundo apabullante que únicamente obedece a sus propias leyes... $\rangle^{79}$ Viene insistiendo Cerezuelle en que el reconocimiento de la autonomía de la técnica no conduce necesariamente a posiciones ludistas, «antitécnicas», sino sólo a su control. Con «autonomía de la técnica» quiere decirse que aplicaciones muy importantes de la técnica escapan, de hecho, a las elecciones individuales y colectivas y que son el resultado de un funcionamiento propio de la técnica. Y éste no ofrece más que un reducido espacio propio a las decisiones y preferencias morales, culturales o políticas. Cierto es que la noción de una técnica autónoma resulta inquietante en la medida en que, si está fundamentada, no puede ya contentarse, la sociedad actual, con la tradicional llamada a los valores y al voluntarismo político para dominar y orientar nuestra vida social. Si la autonomía quedara confirmada por los hechos, esa realidad debería conducirnos 
a la revisión, aunque fuera en los mínimos, de la idea dominante de progreso y, en particular, de la relación entre razón y libertad. Quizá por eso resulte tan difícil someter a juicio esta cuestión: la importancia de las consecuencias entrevistas, avisa Cerezuelle, bloquea el debate de los hechos. A menudo, la asunción de concepciones progresistas y racionalistas del hombre conduce, "casi automáticamente, al rechazo de la idea de autonomía de la técnica, porque este modelo sería, a priori, incompatible con la libertad del hombre..${ }^{80}$ Así, para Georges Balandier, la expansión técnica hace cada vez menos distintas la realidad y la ficción. La máquina se interpone en las relaciones sociales, hace del hombre un recurso, una pieza más, perfectamente reemplazable. Pero los fallos del sistema, dice Balandier, no son imputables a la máquina, sino al factor humano, que ha falseado en su esencia (medios-fines) las relaciones entre los elementos componentes. La ingeniería genética sería un ejemplo de la combinación entre lo natural y lo artificial. Pero Balandier no cree en la autonomía de las técnicas. Siempre hay oportunidades para la toma de decisiones, sostiene.

La autonomía de la técnica no puede predicarse más que en términos sociológicos, sostiene Cerezuelle: «Por medio de la inferencia, no es suficiente la definición de principios morales para regular tal o cual uso particular de las técnicas. (Cuando los medios se vuelven contra el hombre e imponen su propia lógica) la creación de un contexto técnico compatible con una acción auténticamente humana deviene una prioridad, es decir, hay que preservar la posibilidad de una responsabilidad efectiva.» ${ }^{81}$ Por lo cual, la elección esencial concierne a la legitimidad de la existencia misma de los instrumentos técnicos. De modo que Cerezuelle hace suyos los enfoques de William Vandenburg y Jacques Ellul en su propuesta de une éthique du non-pouvoir, como medio racional de posibilidad de elección y responsabilidad ante el uso de las técnicas.

Ellul se limitó, a este respecto, a poner en evidencia la autonomía de la técnica. Ni siquiera hizo hincapié en sus efectos. Por su parte, aduce Florman que la técnica no es un poder autónomo ni, menos todavía, totalitario, sino una mera extensión de los deseos y necesidades del género humano y una característica privativa de la condición humana ${ }^{82}$ La obra de Ellul no sería más que un trágico lamento, más o menos ilustrado, una manifestación nostálgica que propugnaría un desarrollo social que sería más fructífero si prescindiera de tantos avances tecnológicos. La crítica de Florman, como la de Falk, no puede ser más endeble y reduccionista. Simplemente, parece que no hayan comprendido nada. La técnica, para Ellul, no es sólo un resultado. Ni siquiera un proceso. Es un tipo de racionalidad. Esto es lo que escapa a la comprensión de Falk y Florman, como a la de tantos otros. Y se manifiesta, ese tipo de racionalidad, como un conjunto de elementos interdependientes, con funcionalidad propia y derivada. Tales elementos son las técnicas que sirven como medios -las operaciones técnicas-y las técnicas que actúan como fines, producto de su propia racionalización y constructores de una 
trascendencia privativa. ${ }^{83}$ La clave de las decisiones técnicas reside en su inserción funcional en el sistema técnico. La idea de la técnica que Howard Falk y Samuel Florman hacen suya es la que corresponde a la posición mayoritaria. La técnica no sería sino la extensión, material, operativa y neutral, del brazo humano. Es una idea común a casi todos los adversarios de las tesis ellulianas. Un sistema de medios que llevan a fines predeterminados. Sin más. En cuya virtud, no puede haber contradicción entre la técnica y la condición humana sino una identidad natural. Es lo que obliga, a tantos, a rechazar el «pesimismo» elluliano y su concepción de la técnica como un nuevo e ineluctable principio de dominio universal. 


\section{NOTAS}

${ }^{1}$ ELLUL, J., (1954): La Technique ou L'Enjeu du siècle, Armand Colin, Paris. Citamos según la reed. en Economica, Paris, 1990, p. 2. En adelante, T.S.

${ }^{2}$ «E. Dühring, P. Duhem, E. Mach y Boltzmann en mécánica y física, Kopp en química, Cantor en historia de la matemática, últimamente en forma de síntesis sociológica C. Bouglé, en las ciencias biológicas de la naturaleza Radl, en la psicología Bergson, Scheler, Grünbaum, han mostrado cuán fuerte fue el llamado impulso técnico (en cursiva en el original) para la aplicación de esquemas mecánicos a los hechos; cómo transforman la imagen teorética (en cursiva en el original) de los hechos en un modo peculiar y siempre más o menos mecánico-formal, dentro de la matemática pura, los problemas científico-naturales de la aplicación en física; dentro de las ciencias exactas en general, problemas tecnológicos; dentro de la tecnología, problemas técnico-prácticos de la industria, de la técnica de las fortificaciones, de la guerra y de las comunicaciones, más la técnica científica del experimento y de la medida; incluso dentro de la biología, los impulsos recibidos de los criadores de animales y plantas, de la diagnosis y de la terapeútica de las enfermedades; dentro de la psicología, la técnica de la dirección y la derivación de las almas en la pedagogía y en la política (desde los ejercicios de San Ignacio, fundados en ideas de psicología asociacionista inglesa, hasta la moderna psicología aplicada y el 'psicoanálisis' médico).» (SCHELER, M., (1973): Sociología del saber, Siglo XX, Buenos Aires, p. 145.)

${ }^{3}$ Después de la II Guerra Mundial, cundió en la sociología europea -y, sobre todo, la francesa- una idea que Le Coeur (en Le Rite et l'Outil) había expuesto de forma muy sencilla. El rito simbolizaba lo que, en términos marxianos, podía denominarse superestructura. La herramienta formaba parte de lo que el lenguaje durkheimiano venía llamando sustrato. El sustrato material de los grupos sociales recogía las representaciones y las acciones sociales en el doble aspecto geográfico y demográfico (para la escuela de Durkheim) y de su técnica (el tercer elemento, para Mauss.) (Vide el magnífico análisis, al respecto, de CUVILLIER, A., (1954): Manuel de Sociologie, dos tomos, PUF, Paris, pp. 234 y ss.) Ya había advertido Mauss que lo que impedía a las concepciones «interpsicológicas» de los fenómenos sociales la comprensión de las características específicas de tales fenómenos era su insistencia en separar el «espíritu de grupo» de su sustrato material. (Vide, MAUSS, M., (1971): Sociología y Antropología, Tecnos, Madrid).Y, precisamente, escribía Maurice Halbwachs que «las formas materiales de la sociedad» son las que empujan a la propia sociedad, «no en virtud de un imperativo físico, como actuaría una masa sobre otra, sino por la conciencia que hacemos nuestra en tanto que miembros de un grupo que percibe su volumen, su estructura física y sus movimientos en el espacio». Por «formas de producción», entendía Halbwachs «las condiciones técnicas (...) en primer lugar, la técnica». Ahora bien, «las agrupaciones por razones técnicas 
no llegan a configurar grupos realmente sociales.» (HALBWACHS, M., (1938): Morphologie sociale, A. Colin, Paris, p. 40.) Citamos según la reed. de 1970.) Propone Cuvillier que se añada, a los elementos presentados por el gran sociólogo de la memoria colectiva, «la técnica, sus procedimientos de acción sobre la naturaleza.» (Ibid., pág. 237.)

${ }^{4}$ ADORNO, T.W., (1976): Consignas, Amorrortu, Buenos Aires, p. 91.

${ }^{5}$ ELLUL, J., T.S., p. 4.

${ }^{6}$ LOVEKIN, D., (1991): Technique, Discourse and Consciousness, Lehigh University Press, Bethlehem, p. 162, apoyándose en la fenomenología husserliana. ${ }^{7}$ «Pero parece que hay en los fines alguna diferencia, porque unos de ellos son acciones y otros, fuera de las acciones, son algunas obras; y donde los fines son algunas cosas fuera de las acciones, allí mejores son las obras que las mismas acciones. Pero como sean muchas las acciones y las artes y las sciencias, de necesidad han de ser los fines también muchos.» (ARISTÓTELES, (1984): Ética a Nicómaco, Traducción de Pedro Simón Abril, I, 1, 1094, a 5-10, vol. I, Orbis, Barcelona).

${ }^{8}$ También Paulino Garagorri califica a la técnica de «fenómeno», «de tan invasora presencia en el mundo contemporáneo...» («Nota preliminar»a ORTEGA Y GASSET, J., (1996): Meditación de la técnica y otros ensayos sobre ciencia y filosofía, Revista de Occidente-Alianza, Madrid, p. 6.)

${ }^{9}$ HEIDEGGER, M., (1989): «La pregunta por la técnica», Anthropos, Suple. n. 14. ${ }^{10}$ FEENBERG, A., (1991): Critical Theory of technology, Oxford University Press, Nueva York, sobre todo, pp. 5-13.

${ }^{11}$ Vide, IHDE, D., (1983): Existential technics, State University of New York Press, Albany. Vide el magnífico estudio comparativo entre las posiciones de Friedrich Dessauer y Heidegger: TUCHEL, K., «Friedrich Dessauer as Philosopher of Technology: Notes on his Dialogue with Jaspers and Heidegger», en DURBIN, P. (ed.), (1982): Research in Philosophy and Technology, vol. 5, JAI Press, Greenwich, pp. 269-280; DESSAUER, F., (1964): Discusión sobre la técnica, Rialp, Madrid. ${ }^{12}$ CHRISTIANS, C.G., «Technology and Triadic Theories of Mediation», en HOOVER, S.M. y LUNDBY, K. (eds.), (1997): Rethinking Media, Religion and Culture, Sage, Londres, pp. 65-82 y p. 70 .

${ }^{13}$ «Un científico puede aceptar... las formulaciones más inadecuadas y engañosas de sus propios principios científicos sin darse cuenta de lo que se dice, porque automáticamente lo complementa con su conocimiento tácito de lo que la ciencia es realmente, consiguiendo así que la formulación parezca adecuada.» (POLANYI, M., Personal Knowledge, Routledge, Londres, 1958, p. 169; citado por NASH, L.K., (1963): The Nature of the Natural Sciences, Brown, Boston, p. 322; citado, a su vez, por MERTON, R.K., (1980): Ambivalencia sociológica y otros ensayos, Espasa-Calpe, Madrid, p. 77.)

${ }^{14}$ ORTEGA y GASSET, J., op. cit., p. 87.

${ }^{15}$ SHRADER-FRECHETTE, K., (1985): Risk Analysis and Scientific Method, 
Reidel, Dordrecht. (Y de la misma autora, (1985): Science Policy, Ethics, and Economic Methodology, Reidel, Dordrecht, en la línea de RAWLS, J., (1979): Teoría de la Justicia, FCE, Madrid.)

${ }^{16}$ «La valoración de la tecnología se centra en las consecuencias latentes de desarrollos tecnológicos ya existentes o propuestos. Está pensado (el Technology Assessment) para descubrir previamente consecuencias desconocidas o no consideradas de complejos tecnológicos ya existentes o propuestos que tengan importancia social, ecológica o a cualquier otro nivel humano.» (MERTON, R.K., Ambivalencia sociológica y otros ensayos, p. 207.)

${ }^{17}$ ELLUL, J., (1988): Le Bluff Technologique, Hachette, Paris, p. 186. El autor citado ha defendido esas posiciones en SALOMON, J.J.,(1981): Prométhée empêtré, Pergamon, Paris ; vide, también, SALOMON, J.J., y SCHMEDER, G., (1986): Les Enjeux du changement technologique, Economica, Paris.

${ }^{18}$ SCARDIGLI, V., (1983): La Consommation, culture du quotidien, PUF, Paris. ${ }^{19}$ ELLUL, J., Le Bluff technologique, p. 186.

${ }^{20}$ ID., Ibid. p. 188.

${ }^{21}$ JONAS, H.,(1984): The Imperative of Responsibility: In Search of an Ethics for the Technological Age, University Chicago Press, Chicago.

${ }^{22}$ DAHLSTROM, D., «Lebenstechnik und Essen: Towards a Technological Ethics after Heidegger», en DURBIN, P.T. (ed.), (1987): Technology and Contemporary Life (Philosophy and Technology, vol. 4) Reidel, Dordrecht, pp. 145-160.

${ }^{23}$ BORGMANN, A., (1984): Technology and the Character of Contemporany Life, University of Chicago Press, Chicago.

${ }^{24}$ Vide, TOYNBEE, A.J.,(1985): Estudio de la Historia, 3 vols., Planeta-Agostini, Barcelona; BURNHAM, J., (1962): La Revolución de los Directores, Huemul, Buenos Aires.

${ }^{25}$ ELLUL, J., T.S., p.10.

${ }^{26}$ No se mostró de acuerdo, Mauss, con la noción de los fenómenos morfológicos propia de la escuela durkheimiana, que tendía a su reducción en fenómenos geográficos y demográficos. Si la morfología social estudiaba los grupos sociales en tanto que fenómenos materiales, no podía ignorar la observación de los medios materiales disponibles para enfrentarse al entorno, esto es, su técnica. ( En «Divisions et proportions des divisions de la Sociologie», en (1927):L'Année Sociologique (nueva serie, que dirigía el propio Marcel Mauss), Alcan, Paris, t.II, p. 98 y ss.) ${ }^{27}$ ELLUL, J., T.S., p. 12.

${ }^{28}$ FOURASTIÉ, J., (1951): Machinisme et bien-être, Minuit, 1951. (Citado por Ellul en T.S. pág.13.) El título del libro de Fourastié es, en realidad, Machinisme et bienÉtre, niveau de vie et genre de vie en France de 1700 à nous jours, Minuit, Paris. En (1949): Le Grand espoir du XXe siècle, P.U.F., Paris, (Ellul no ha prestado atención a este libro), respondía Fourastié, en una línea más optimista que Georges Friedmann, a la ingenuidad con que afrontaban la inhumanidad técnica autores 
tales como Henry Le Chatelier: «Cualquier producto industrial es una función determinada de ciertos factores y puede expresarse mediante una fórmula algebraica.» (Citado por CUVILLIER, A., op. cit. p. 424. El texto citado se incluye en (1920): Le Taylorisme, Dunod, Paris, p. VII.) A estos efectos, también FOURASTIÉ, J., (1947): La Civilisation de 1960, P.U.F., Paris.

${ }^{29}$ ELLUL, J., T.S., p. 101.

${ }^{30}$ FRIEDMANN, G., (1966): «7 études sur l'homme et la Technique», Gonthier, Paris.

${ }^{31}$ LASSWELL, H.D., (1952): Effets de la technologie, Unesco, (citado en T.S., p. 16.) Al editor norteamericano de T.S. ((1964): The Technological Society, Alfred A. Knopf, Nueva York) se le olvidó incluir la cita referida. Sorprende, por otro lado, que Ellul desconociera el primer escrito que Harold D. Laswell había publicado en Francia, repleto de referencias al mundo de la técnica: «Les sciences de la politique aux E.-U.», en Cahiers de la Fondation nationale des Sciences Politiques, (1951): núm. 19, s/p. Vide, también, ID., (1974): La política como reparto de influencia, Aguilar, Madrid. ${ }^{32}$ ELLUL, J., T.S., p. 17.

${ }^{33}$ «...toda técnica consiste en dos cosas: una, invención de un plan de actividades, de un método, procedimiento -mechané, decían los griegos-, y otra, ejecución de ese plan. Aquélla es en sentido estricto la técnica; ésta es sólo la operación y el obrar.» (ORTEGA Y GASSET, J., op. cit., p. 82.)

${ }^{34}$ ELLUL, J., T.S., p. 121.

${ }^{35}$ ID., Ibid., p. 40.

${ }^{36}$ TCHAKOTINE, S., (1939): Le Viol des foules par la propagande, Gallimard, Paris, (citado por ELLUL, J., T.S., p. 309.)

${ }^{37}$ Vide, ALLĖGRE, C., (1995): La Défaite de Platon, Fayard, Paris.

${ }^{38}$ MAUCORPS, P.H., (1950): Psychologie des mouvements sociaux, P.U.F., Paris, (citado por ELLUL, J., en T.S., p. 310.)

${ }^{39}$ ELLUL, J., (1977): Le Système technicien, Calmann-Lévy, Paris, p. 278.

${ }^{40}$ ELLUL, J., T.S., p. 6.

${ }^{41}$ «Hay quien cree que la técnica actual está más firme en la historia que otras porque ella misma, como tal técnica, posee ingredientes que la diferencian de todas las demás, por ejemplo, su basamento en las ciencias. Esta presunta seguridad es ilusoria. La indiscutible superioridad de la técnica presente, como tal técnica, es, por otro lado, su factor de mayor debilidad. Si se basa en la exactitud de la ciencia, quiere decirse que se apoya en más supuestos y condiciones que otras, al fin y al cabo, más independientes y espontáneas» (ORTEGA Y GASSET, op. cit., p. 40.) ${ }^{42}$ Vide la posición de Scheler: «Ni las necesidades técnicas condicionan la nueva ciencia (como dice, viendo las cosas sólo por un lado, Spengler), ni la nueva ciencia condiciona el progreso técnico y el capitalismo (A. Comte), sino que en el tipo de la nueva humanidad burguesa, de su nueva estructura de impulsos y su nuevo ethos están igualmente fundadas la original transformación del sistema de las categorías 
lógicas de la nueva ciencia y el nuevo impulso técnico, no menos original, que empuja a la dominación de la naturaleza. La técnica y la ciencia necesitan, por ende, coexistir en la fructífera acción recíproca en que se hallan, y se 'ajustan' una a otra...» (SCHELER, M., op. cit., pp. 158-159.)

${ }^{43}$ Este sentido de la técnica es el que Michel Henry quiere desvelar: «(La técnica) es un conjunto de operaciones y de transformaciones que extraen su posibilidad de la ciencia y de su saber teórico, con la exclusión de cualquier otra forma de saber, con la exclusión de toda referencia al mundo-de-la-vida y a la vida misma. No obstante, la esencia de la técnica, en su doble relación, positiva para con la ciencia, negativa para con la vida, es difícil de captar. Hay que proponer una elucidación sistemática de la misma.» (HENRY, M., (1997): La Barbarie, Caparrós, Madrid, p. 61.)

${ }^{44}$ ELLUL, J., T.S., p. 8.

${ }^{45}$ ID., Ibid., p. 15.

${ }^{46}$ ID., Ibid., p. 19.

${ }^{47}$ ID., Le Bluff technologique, p. 69.

${ }^{48}$ ID., T.S., p. 132.

${ }^{49}$ WINNER, L., (1977): Autonomous Technology: Technics-Out-Of Control as a Theme in Political Thougth, MIT Press, Cambridge.

${ }^{50}$ ELLUL, J., T.S., p. 65.

${ }^{51}$ ID., Ibid., p. 69.

${ }^{52}$ ID., Ibid., p. 72.

${ }^{53}$ ID., Ibid. «Esta racionalidad que se ve particularmente bien en los hechos de racionalización, de división del trabajo, de creación de las rutinas o de normas de producción, implica en realidad dos movimientos: a) La intervención, en toda operación, de un 'discurso', bajo los dos aspectos que este término puede tomar (de un lado, la intervención de una reflexión voluntaria, de otro lado la intervención de medios de un término a otro) excluye la espontaneidad y la creación personal. b) El otro aspecto de este movimiento consiste en reducir este discurso a su única dimensión lógica. Toda intervención de la técnica es, en efecto, una reducción, al esquema lógico, de los hechos, pulsiones, fenómenos, medios, instrumentos.» (Ibid., p. 73.) ${ }^{54}$ En Le Système technicien (pp. 137 y ss.), Ellul refiere las categorías del fenómeno técnico agrupándolas en la unicidad, la autonomía, la universalidad y el holismo, pero reafirma la capacidad evolutiva y cambiante de la técnica. Y, en el mismo libro, más adelante, establece Ellul las características del progreso técnico: el autocrecimiento, el automatismo, la progresión causal y la ausencia de finalidad, y el problema de la aceleración. Con la adición de la progresión causal y la ausencia de finalidad, y los problemas de aceleración, Ellul quiere recalcar la naturaleza sistémica del fenómeno técnico.

${ }^{55}$ ELLUL, J., T.S., p. 81. Michel Henry coincide plenamente con Ellul, al respecto: «Así nos encontramos en presencia de un conjunto de dispositivos instrumentales, de maneras de hacer, de operaciones, de procedimientos cada vez más eficaces y 
sofisticados, cuyo desarrollo, no obstante, no conoce otros estímulos ni otras leyes que los que él mismo crea y de esta forma se despliega como un autodesarrollo. El autodesarrollo de una red de procesos fundados en el saber teórico de la ciencia, pero dejados a sí mismos, jugando consigo mismos y para sí mismos, reobrando consiguientemenete sobre ese saber, suscitándolo y provocándolo, como su causa verdadera finalmente, en lugar de dejarse determinar por él. Tal es la esencia de la técnica moderna.» (HENRY, M, op. cit., p. 62.)

${ }^{56}$ CAMICHEL, Ch., Travail et Techniques, (citado por ELLUL, J., en T.S., p. 87, que no presenta más datos. En la edición en inglés de T.S., ni siquiera aparece esta cita.)

${ }^{57}$ ELLUL, J., T.S., p. 88.

${ }^{58}$ «La sociedad necesita prever globalmente. ¡La sociedad no acepta el presente más que como una preparación al futuro! (...) Todo se concibe en función del porvenir, con lo que el crecimiento se convierte en una necesidad económica. Nuestra construcción económica y técnica no es, en realidad, más que un movimiento. Nuestra riqueza no es tal si no continúa creciendo...» (PARTANT, F., (1978): Que la crise s'aggrave, Solin, Paris, 1978. Citado por ELLUL, J., en Le Bluff technologique, p. 101.)

${ }^{59}$ Relacionada con las «predicciones autodestructivas», vide MERTON, R.K., Ambivalencia sociológica y otros ensayos, pp. 184-185.

${ }^{60}$ ELLUL, J., Le Bluff technologique, p. 451.

${ }^{61}$ LAGADEC, P., (1981): La Civilisation du risque, Le Seuil, Paris, (citado por ELLUL, J., en Le Bluff technologique, p. 183.)

${ }^{62}$ «El pensamiento prospectivo cree, en su optimismo débil, que el siglo XXI recogerá los frutos maduros del progreso de la humanidad. Pero, de hecho, los prospectivistas han edificado un mundo imaginario a partir de un presente abstracto.» (MORIN, E., (1982): Para salir del siglo XX, Kairos, Barcelona. Citado por ELLUL, J., en Le Bluff, technologique, p. 104.) La visión de Ellul y Morin parece un tanto cruel con el pensamiento de la prospectiva. Desde que la Rand Corporation, un thinktank fundado en 1946, llevó adelante, por cuenta del Pentágono, un análisis sobre la evolución de las técnicas armamentísticas para ampliar sus investigaciones al campo de la geoestrategia, la prospectiva ha ido enriqueciéndose con las aportaciones de múltiples saberes que confluyen en la previsión de distintos futuros probables. Gaston Berger, el fundador del francés Centre d'études prospectives, fue el primero en utilizar el término «prospectiva», un neologismo opuesto al de «retrospectiva». Y sus métodos y técnicas no son tan despreciables. Así, las encuestas Delphi recogen y tratan sistemáticamente las opiniones sobre la probabilidad de suceso de un acontecimiento determinado. Los «árboles de decisión», los «impactos cruzados»o el «análisis estructural» permiten la inteligibilidad de las variables más relevantes, el establecimiento de relaciones de causalidad entre ellas y la evaluación de los distintos escenarios probables. Incluso existen técnicas cualitativas susceptibles de aplicación a la prospectiva que han mostrado sobradamente su fiabilidad. El método por excelencia es el de «los escenarios», dirigido a la identificación de las variables 
esenciales y al establecimiento de las «dimensiones de incertidumbre», las más probables y significativas. Con todo, nadie se atreve a asegurar el estatuto científico de la prospectiva. Por el momento, no pasa de ser un método descriptivo. Una actividad casi poiética, en el sentido heideggeriano. Vide, CAZES, B., (1986): L'Histoire des futurs, Seghers, Paris; WICKHAM, S. (comp.), «Prospective dans un monde turbulent», en (1991): Economie appliquée, Archives de l'ISMEA, n. 4; GODET, M., (1992): De l'anticipation à l'action, Dunod, Paris.

${ }^{63}$ «¿Habrá que recordar los considerables errores de las previsiones de Hermann Kahn? (Se refiere, Ellul, a las anticipaciones que aparecen en KAHN, H., y WIENER, A.J., (1969): El año 2000, Revista de Occidente, Madrid. ) ¿Y los de Fourastié, que escribió nada más acabar la guerra un pequeño libro de previsión de la civilización de 1960, y nada de lo que previó se ha verificado? (Se trata de FOURASTIÉ, J, (1947): La Civilisation de 1960 , PUF, Paris. Cfr. con la posición de Ellul la de MINOIS, G., (1996): Histoire de l'avenir. Des prophètes à la prospective, Fayard, Paris; especialmente las referencias a Jean Fourastié, Gaston Berger, Bertrand de Jouvenel y Hugues de Jouvenel y Futuribles.) ¿Habrá que recordar que los economistas no pudieron prever ninguno de los grandes fenómenos económicos acaecidos entre 1950 y 1980, ni la crisis del petróleo o el hundimiento de la productividad en los Estados Unidos? ¿Habrá que remitirse a lo que parecía el trabajo más riguroso, en vista de la abundancia de hechos y parámetros utilizados, el famoso Informe del Club de Roma con la ayuda del M.I.T.? Después de diez años, todas las previsiones se han derrumbado.» (ELLUL, J., Le Bluff technologique, p. 105.) No obstante, Ellul quiere señalar el mérito de algunos estudios de la previsión. Así, el de BRESSAND, A. y DISTLER, C., (1985): Le Prochain Monde, Le Seuil, Paris. La previsión ha conocido «dos períodos: la predicción (y la 'predicación' en los años 30); después, la previsión de carácter científico a partir de 1960, con Daniel Bell, descartando los juicios personales y fantasiosos. (...) Las estrategias aplicadas en los años 60 eran estrategias de crecimiento y no de gestión de la escasez. (...) Sin embargo, dicen esos autores, estos trabajos eran ajustados y esenciales, pues hacían emerger la idea del 'tiempo estratégico': 'Los conceptos utilizados para prever dependen de los problemas, temas e interrogantes característicos de un período dado'.» Pero Bressand y Distler se equivocan, señala Ellul, cuando sostienen que el sistema técnico depende, únicamente, del principio de eficacia.

${ }^{64}$ «La Prévoyance comienza cuando nos hacemos a la idea de haber creado una civilización de riesgo, según la excelente fórmula y la demostración de Patrick Lagadec. Su teoría del 'Riesgo tecnológico mayor' me parece irrecusable, aunque haya sido tan mal acogida. Y su análisis de las actitudes sociales frente al riesgo tecnológico mayor es, a mi modo de ver, ejemplar: el industrial quiere producir a toda costa, incluso creando graves riesgos. El Estado quiere proteger la actividad productiva... El ciudadano ignora, es impotente, y finalmente acepta ese riesgo mal conocido en compensación por las satisfacciones que le aporta la sociedad técnica. 
En cuanto al experto, siempre se sitúa al margen del riesgo.» (LAGADEC, P., (1981): La Civilisation du risque, Le Seuil, Paris. Citado por ELLUL, J.,en Le Blufftechnologique, p. 123.) Vide, además, contra la teoría tecnocrática del «riesgo mínimo medio», GIARINI, O. y LOUBERGÉ, H., (1979): La Civilisation technicienne à la dérive, Dunod, Paris ; COMMONER, B., (1992): En paz con el planeta, Crítica, Barcelona. No obstante, no puede ignorarse el esfuerzo protagonizado por el mundo industrial en la prevención y tratamiento de los riesgos a medida que van mostrándose. De hecho, se ha levantado un impresionante complejo de industrias destinadas al control de los efectos nocivos del desarrollo industrial. Además, se incrementan exponencialmente las reglamentaciones, cada vez más precisas, para la previsión de riesgos.

${ }^{65}$ En cuanto a la gestión de la incertidumbre, GIARINI, O. y LOUBERGÉ, H., op. cit. ${ }^{66}$ «La imposibilidad de una información exacta» era ya la hipótesis central de MORGENSTERN, O., (1971): Précision et incertitude des données économiques, Donod, Paris. Por su parte, MORIN, E., (1981): Pour sortir du XXe siècle, Nathan, París, «señala con mucha justeza que el progreso de los media potenció una extraordinaria red de información que ha provocado el progreso de la desinformación y la ignorancia.» (Citados por ELLUL, J., en Le Bluff technologique, p. 113.). Vide, a los efectos de la llamada «integración informacional», GRAMSTEDT, I., (1980): L'Impasse industrielle, Le Seuil, Paris.

${ }^{67}$ Advierte Janicaud que «nos hemos sumergido en un plexo de poder, en su absoluta novedad, en su vertiginosa imprevisibilidad. Sobrecogedora novedad en el carácter irreversible de los fenómenos...» (JANICAUD, D., (1985): La Puissance du rationnel, Gallimard, Paris. Citado por ELLUL, J., en Le Bluff technologique, p. 119.)

${ }^{68}$ ELLUL, J., T.S., p. 101.

${ }^{69}$ ID., Ibid., p. 89. Vide, DOU, A., et al., (1980): Aspectos éticos del desarrollo tecnológico, Mensajero, Barcelona.

${ }^{70}$ ELLUL, J., T. S., p. 91.

${ }^{71}$ «Cuando la técnica se deja a ella misma, es decir, a una lógica de potestad, es igual para lo mejor que para lo peor o para nada.» La fe en la técnica es la ruina de la ética y la derrota de las ideas (técnicamente posible como mecánicamente realizable) «sobre todo cuando la dimisión de las ideas de libertad, igualdad y fraternidad y la codicia economicista de la eficiencia hacen que todo lo que sea técnicamente realizable se considere como mecánicamente realizado.» (CEREZUELLE, D., «Reflexions sur l'autonomie de la technique», en HOTTOIS, G. (ed.), (1988): Evaluer la technique, Vrin, Paris, pp. 97-116, p. 97.)

${ }^{72}$ ELLUL, J., T. S., p. 92.

${ }^{73}$ FLORMAN, S., (1976): The Existential Pleasures of Engineering, St. Martin's Press, Nueva York, pp. 65 y ss.

${ }^{74}$ ELLUL, J., T.S., p. 113.

${ }^{75}$ ID., Ibid., p. 106. 
${ }^{76}$ ID., Ibid., p. 120.

${ }^{77}$ ID., Le Bluff technologique, p. 9.

${ }^{78}$ ID., T.S., p. 121.

${ }^{79}$ ID., Ibid., p. 12. Por su parte, Michel Henry concluye: «Techné designa, de una manera general, un 'saber-hacer'. Pero la esencia original de la técnica no es un saber-hacer particular, sino el saber-hacer como tal, un saber que consiste en el hacer, es decir, un hacer que lleva en él su propio saber y lo constituye.» (HENRY, M., op. cit., p. 62.) No escasean, precisamente, los libros que tratan el problema de la autonomía de la técnica. Vide, especialmente, los escritos de Cerezuelle. Además, DUMOUCHEL, P., y DUPUY, J.-P., (1893) L'Auto-organisation, Le Seuil, Paris; DUPUY, J.-P., (1982): Ordres et Désordres, Le Seuil, Paris; CASTORIADIS, C., (1978) Les Carrefours du labyrinthe, Le Seuil, Paris; LUSSATO, B., (1981) Le Défi informatique, Fayard, Paris; ROQUEPLO, Ph., (1983) Penser la technique, Le Seuil, Paris.

${ }^{80}$ CEREZUELLE, D., op. cit., p. 99.

${ }^{81}$ ID., Ibid., p. 112.

${ }^{82}$ FLORMAN, S., op. cit., pp. 57-74; FALK, H., (1965): "La Technique", (reseña), Technology and Culture, $\mathrm{n}^{\circ}$ 6, 1965, pp. 532-535.

${ }^{83}$ Es lo que Ellul apunta en el capítulo dedicado a las «Técnicas Humanas» en T. S. y desarrolla con mayor detalle en (1981): La Parole humiliée, Seuil, Paris, y (1980): L'Empire du non sens: L'Art et la société technicienne, PUF, Paris. 